\title{
Impact of maternal overnutrition on gluconeogenic factors and methylation of the phosphoenolpyruvate carboxykinase promoter in the fetal and postnatal liver
}

\author{
Leewen Rattanatray ${ }^{1,2}$, Beverly S. Muhlhausler', Lisa M. Nicholas', Janna L. Morrison' and I. Caroline McMillen
}

BACKGROUND: Exposure to maternal obesity or hyperglycemia increases the risk of obesity and poor glucose tolerance in the offspring. We hypothesized that maternal overnutrition in late pregnancy would result in (i) lower methylation in the promoter region of the cytosolic form of phosphoeno/pyruvate carboxykinase (PEPCK-C; PCK1) and (ii) higher expression of hepatic gluconeogenic factors in the fetal and postnatal lamb. METHODS: Ewes were fed 100\% $(n=18)$ or $~ 155 \%(n=17)$ of energy requirements from $115 \mathrm{~d}$ gestation, and livers were collected at 140 d gestation or $30 \mathrm{~d}$ postnatal age.

RESULTS: Maternal overnutrition resulted in a decrease in hepatic expression of the mitochondrial form of PEPCK (PEPCK-M; PCK2) but not of PEPCK-C or glucose-6-phosphatase (G6PHOS) before and after birth. Hepatic expression of peroxisome proliferator-activated receptor $\gamma$ coactivator 1 (PGC-1), peroxisome proliferator-activated receptor a (PPARa), PEPCK-C, G6PHOS, and $11 \beta$ hydroxysteroid dehydrogenase type 1 (11ßHSD1), but not PEPCK-M, was higher in the postnatal lamb compared with that in the fetal lamb. The level of PCK1 methylation was paradoxically approximately twofold higher in the postnatal liver compared with that in the fetal liver.

CONCLUSION: Maternal overnutrition programs a decrease in hepatic PEPCK-M in the offspring and as $50 \%$ of total hepatic PEPCK is PEPCK-M, the longer-term consequences of this decrease may be significant.

n pregnancies complicated by maternal diabetes mellitus, gestational diabetes, or mildly impaired glucose tolerance, offspring are at risk of developing obesity and glucose intolerance (1-3). It has, therefore, been proposed that exposure to maternal, and hence fetal, hyperglycemia may result in (i) permanent metabolic changes within insulin-sensitive tissues and (ii) the programming of an increased body fat mass, glucose intolerance, and insulin resistance in later life $(4,5)$.

Exposure to maternal overnutrition during the final 30-40 d of gestation in the pregnant ewe results in fetal hyperglycemia and an increase in both fasting plasma glucose concentrations and body fat deposition in the postnatal lamb (6). It is not clear, however, whether the metabolic consequences of exposure to maternal overnutrition are solely due to the increase in body fat mass in the offspring or whether they represent the outcome of programmed changes in insulin-sensitive tissues, such as the liver, in addition to the changes that occur in adipose tissue to increase fat deposition.

Hepatic peroxisome proliferator-activated receptor $\gamma$ coactivator 1 (PGC-1) induces fatty acid oxidation in the liver by coactivating the transcription factor peroxisome proliferatoractivated receptor $\alpha$ (PPAR $\alpha)$; it also induces the expression of the hepatic gluconeogenic enzymes phosphoenolpyruvate carboxykinase (PEPCK-C; PCK1) and glucose-6-phosphatase (G6PHOS). PEPCK is the rate-limiting enzyme that regulates hepatic gluconeogenesis, and it has been shown that exposure to chronic hypoxemia, hypoglycemia, and glucocorticoids increases hepatic PEPCK and gluconeogenesis in fetal sheep (6-9). There is also an increase in hepatic gluconeogenic enzyme activity with increasing gestational age, which is dependent on the normal prepartum rise in fetal cortisol (6).

The enzyme $11 \beta$ hydroxysteroid dehydrogenase type 1 $(11 \beta \mathrm{HSD} 1)$ catalyzes the interconversion of active cortisol and inert 11-dehydrocortisol (10). 11ßHSD1 is highly expressed in the liver, where the reaction direction is $11 \beta$ reduction, potentially resulting in an increase in intrahepatic cortisol. Suppression of hepatic 11ßHSD1 expression and enzyme activity results in the reduced expression of hepatic PEPCK, suggesting that $11 \beta \mathrm{HSD} 1$ plays an important role in maintaining the expression of key glucocorticoid-regulated hepatic transcripts (11). Although exposure to excess prenatal glucocorticoids or poor maternal nutrition can permanently program abnormal glucose metabolism in the offspring (12), it is not known whether maternal overnutrition has an effect on the expression of either the glucocorticoid receptor (GR) or $11 \beta H S D 1$ in the liver either before or after birth.

PEPCK is present in two isoforms in the liver: cytosolic PEPCK (PEPCK-C: PCK1) and mitochondrial PEPCK (PEPCK-M: PCK2). It is well established that the mRNA levels and protein abundance of the cytosolic or inducible form of PEPCK are highly correlated, and the role of PEPCK-C in gluconeogenesis and its transcriptional regulation in development 
have been extensively investigated (13-16). Although 50\% of total PEPCK activity in the livers of most mammals consists of PEPCK-M, relatively little is known about the role of PEPCK-M during development $(13,16)$.

Epigenetic modification of key genes plays a role in metabolic programming through a range of mechanisms, including methylation of $\mathrm{CpG}$ sites (regions where a cytosine nucleotide occurs next to a guanine nucleotide) in the promoter regions of key genes, including PCK1 $(16,17)$. Although maternal undernutrition results in a decrease in the level of methylation in the PCK1 promoter and a concomitant increase in PEPCK-C expression in the fetal baboon liver (18), there have been no studies on the impact of maternal overnutrition on the methylation of the PCK1 promoter in the liver of either the fetus or the offspring. In this study, we have, therefore, investigated the effects of maternal overnutrition during late gestation in the sheep on (i) the expression of PGC-1, PPAR $\alpha$, PEPCK-C, PEPCK-M, G6PHOS, glucose transporter-1 (GLUT-1), GR, and $11 \beta \mathrm{HSD} 1$ and (ii) the level of methylation of the PCK1 promoter at three $\mathrm{CpG}$ sites $(-49,-58$, and -88 relative to the transcription start site) in the liver of fetal and postnatal lamb.

\section{RESULTS}

\section{Maternal Overnutrition and Relative Weights of Fetal and Lamb Liver}

There was no difference in fetal arterial $\mathrm{PO}_{2}$ (control, $22.8 \pm 0.6 \mathrm{~mm} \mathrm{Hg}$; well-fed (WF), $21.8 \pm 0.4 \mathrm{~mm} \mathrm{Hg}$ ), $\mathrm{PCO}_{2}$ (control, $49.9 \pm 0.7 \mathrm{~mm} \mathrm{Hg}$; WF, $51.0 \pm 0.9 \mathrm{~mm} \mathrm{Hg}$ ), or $\mathrm{pH}$ (control, 7.39 \pm 0.002 ; WF, 7.39 \pm 0.005 ) between the WF and control groups throughout late gestation. Maternal plasma glucose concentrations were $3.5 \pm 0.2$ and $3.0 \pm 0.2 \mathrm{mmol} / 1$ in the $\mathrm{WF}$ and control groups, respectively, in late gestation. Mean plasma glucose concentrations were higher in the WF group in both fetuses and lambs (Table 1). Plasma insulin concentrations were higher in fetuses, but not in lambs, in the WF group compared with those in the controls (Table 1). There was no impact of exposure to maternal overnutrition on the plasma cortisol concentrations in either fetuses or lambs (Table 1).

There was no difference between the relative liver weights in fetuses in the WF and control groups at 139-141 d gestation (control, $28.0 \pm 2.3 \mathrm{~g} / \mathrm{kg}$; WF, $26.0 \pm 1.4 \mathrm{~g} / \mathrm{kg}$ ). In the postnatal lambs, however, the relative liver weight was significantly greater in the lambs of the WF group compared with that in the lambs of the control group at $30 \mathrm{~d}$ postnatal age (WF, $21.7 \pm 0.59 \mathrm{~g} / \mathrm{kg}$; control, $19.4 \pm 0.57 \mathrm{~g} / \mathrm{kg} ; P<0.05)$.
Maternal Overnutrition and Hepatic Gene Expression in the Fetal and Postnatal Lamb

Hepatic expression of PEPCK-M mRNA was lower in the fetal and postnatal lambs in the WF group compared with that in the controls (Figure 1a). Although there was also a trend $(P<$ 0.06) for hepatic PEPCK-C mRNA expression to be lower in the fetuses of the WF group, there was no effect of exposure to maternal overnutrition on hepatic PEPCK-C mRNA expression in the postnatal lamb (Figure 1b). There was no effect of exposure to maternal overnutrition on the hepatic expression of PGC-1, PPAR $\alpha$, G6PHOS, GLUT-1, and 11ßHSD1 mRNA, either before or after birth (Figures 2-5). There was also no effect of maternal overnutrition on the hepatic expression of GR either before or after birth (fetal: control, $0.50 \pm 0.20$, WF, $0.62 \pm 0.11$; postnatal: control, $0.44 \pm 0.02$, WF, $0.43 \pm 0.02$ ) or on the expression of G6PHOS mRNA in the postnatal lamb (control, 0.032 \pm 0.005 ; WF, 0.041 \pm 0.005 ).

The levels of expression of PEPCK-C, PGC-1, PPAR $\alpha$, and $11 \beta$ HSD1 mRNA were significantly higher, whereas GLUT-1 mRNA expression was lower, in the liver of the postnatal lamb, compared with the liver of the fetus, and these were independent of the level of maternal nutrition (Figures $\mathbf{1 b}$, 2-5). G6PHOS mRNA levels were not detectable in the fetus but increased after birth in both the control and WF groups. There was no difference in GR mRNA expression between the fetuses and postnatal lambs (fetal: $0.56 \pm 0.21$; postnatal: $0.43 \pm 0.02)$.

Furthermore, there was no relationship between the hepatic expression of these genes and the plasma concentrations of glucose, insulin, or cortisol in either the fetus or the postnatal lamb.

\section{Relationships Between Hepatic PGC-1, PPAR $\alpha$, and Gluconeogenic Gene Expression in the Sheep Fetus and Postnatal Lamb}

There was a direct relationship between the hepatic expression of PGC- 1 and PEPCK-M mRNA $\left(y=6.39 x-0.04 ; r^{2}=\right.$ $0.34, P=0.016, n=14)$ in the fetal but not in the postnatal cohort. In contrast, there was no relationship between hepatic PGC-1 and PEPCK-C mRNA expression before birth. In the postnatal cohort, however, expression levels of both PEPCK-C mRNA $\left(y=18.32 x+3.15 ; r^{2}=0.60, P\right.$ $<0.00001, n=19)$ and G6PHOS mRNA $(y=0.34 x+0.01$; $\left.r^{2}=0.38, P=0.004, n=19\right)$ were directly related to hepatic PGC-1 mRNA expression.

Table 1. Mean plasma concentrations of glucose, insulin, and cortisol in fetuses in late gestation (113-to 139-d gestation) and lambs in the first month of postnatal life

\begin{tabular}{|c|c|c|c|c|}
\hline & \multicolumn{2}{|c|}{ Fetal sheep } & \multicolumn{2}{|c|}{ Postnatal lamb } \\
\hline & Control & WF & Control & WF \\
\hline Mean plasma glucose concentration (mmol/l) & $1.44 \pm 0.14$ & $1.94 \pm 0.11^{*}$ & $5.75 \pm 0.17^{* *}$ & $6.26 \pm 0.11^{*, * *}$ \\
\hline Mean plasma insulin concentration $(\mu \mathrm{U} / \mathrm{ml})$ & $6.78 \pm 0.38$ & $8.83 \pm 0.92^{*}$ & $1.55 \pm 0.22^{* *}$ & $1.84 \pm 0.35^{* *}$ \\
\hline Mean plasma cortisol concentration (nmol/l) & $6.71 \pm 0.38$ & $6.52 \pm 0.38$ & $36.60 \pm 5.45^{* *}$ & $34.06 \pm 4.04^{* *}$ \\
\hline
\end{tabular}




\section{PCK1 Promoter Methylation}

The level of methylation at each of the three CpG sites in the PCK1 promoter was relatively low $(\sim 3-10 \%)$ in the late-gestation sheep fetus (Table 2). There was no impact of maternal overnutrition on the level of methylation at any of the $\mathrm{CpG}$ sites in PCK1 in the liver of either the late-gestation sheep fetus or the postnatal lamb (Figure 5). The level of methylation at each site increased significantly, however, after the transition from fetal to postnatal life (Figure 5).

\section{DISCUSSION}

\section{Maternal Overnutrition and Liver Growth in the Offspring}

Although previous studies have shown that exposure to maternal global undernutrition or low-protein diets results in altered liver growth and morphology (19-24), this study has found that there is an impact of maternal overnutrition in late pregnancy on the liver size in early postnatal life. Interestingly,
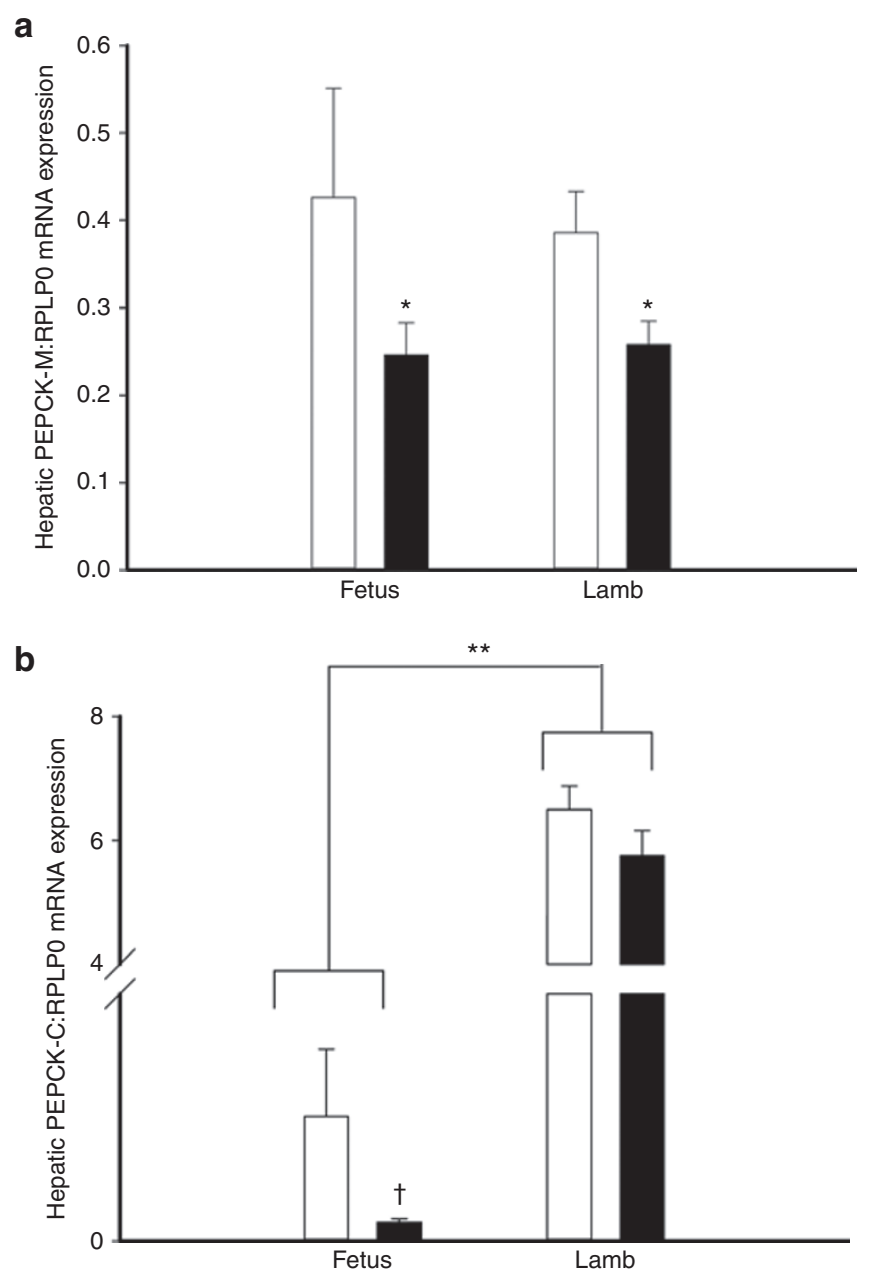

Figure 1. Hepatic mRNA expression of mitochondrial and cytosolic PEPCK in control and well-fed groups. (a) PEPCK-M mRNA expression in fetal and lamb livers in control (open bars) and well-fed (WF; closed bars) groups. *Denotes a significant difference when compared with the control group $(P<0.05)$. PEPCK, phosphoenolpyruvate carboxykinase. (b) PEPCK-C mRNA expression in fetal and lamb livers in control (open bars) and WF (closed bars) groups. **Denotes a significant difference between the level at 1 month of age and that at 139 - to $141-\mathrm{d}$ gestation $(P<0.001)$. ${ }^{\dagger}$ Denotes that the level of difference between the WF and the control groups was at the $P=0.06$ level. there is also evidence that gestational diabetes is associated with an increase in liver size in the human fetus in midgestation (25). Previous studies in the rodent have shown that highfat feeding during pregnancy results in an increase in both liver weight (26) and liver triglyceride content in the offspring $(26,27)$. Similarly, experimental induction of gestational diabetes in the rodent results in postnatal obesity and changes in liver fatty acid composition and very-low-density lipoprotein lipid concentrations (28). Exposure to maternal overnutrition during late pregnancy results in an increase in subcutaneous body fat mass in the postnatal lamb, but this occurs in the absence of an increase in circulating free fatty acid concentrations (29). Although an increase in lipid deposition in the liver appears unlikely to explain the increase in liver size in WF lambs, an increase in liver triglyceride content requires further investigation. An alternative explanation may be that an increase in fetal substrate supply programs an upregulation of the expression of hepatic growth factors to induce hypertrophy
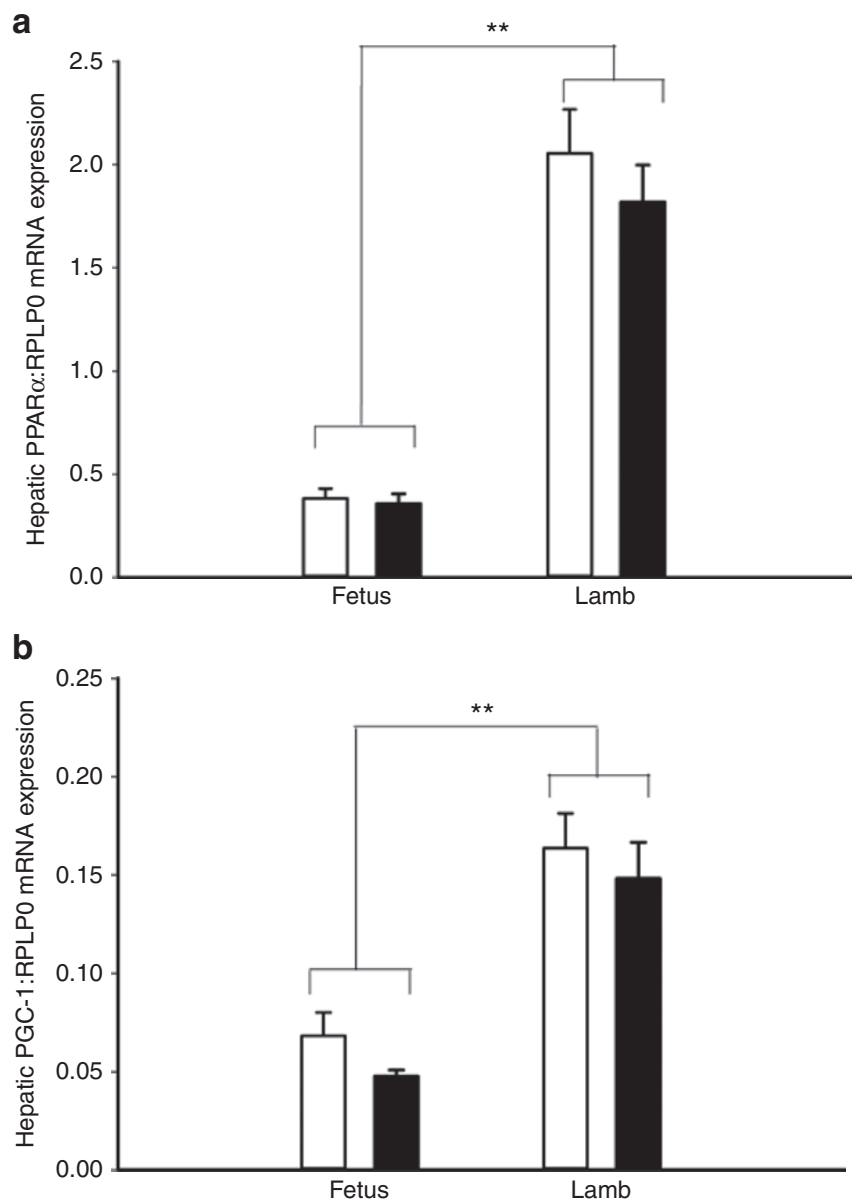

Figure 2. Hepatic mRNA expression of peroxisome proliferator-activated receptor $a$ and peroxisome proliferator-activated receptor $\gamma$ coactivator in control and well-fed groups. (a) Peroxisome proliferator-activated receptor $\alpha(P P A R \alpha)$ mRNA expression in fetal and lamb livers in control (open bars) and well-fed (WF; closed bars) groups. **Denotes a significant difference between the level at 1 month of age and that at 139- to 141-d gestation $(P<0.01)$. (b) Peroxisome proliferator-activated receptor $\gamma$ coactivator (PGC-1) mRNA expression in fetal and lamb livers in control (open bars) and WF (closed bars) groups. **Denotes a significant difference between the level at 1 month of age and that at 139 - to $141-d$ gestation $(P<0.01)$. 


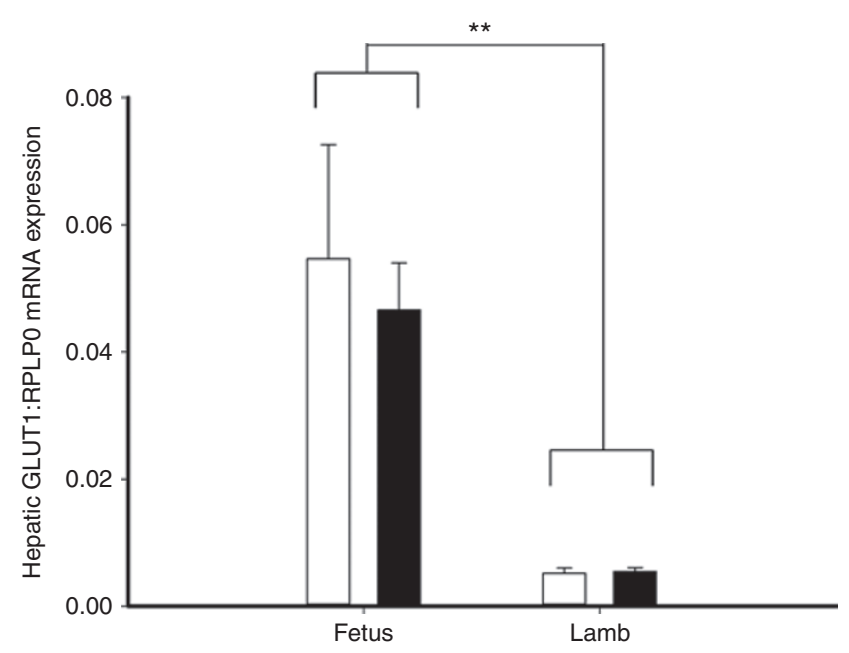

Figure 3. Glucose transporter-1 (GLUT1) mRNA expression in fetal and lamb livers in control (open bars) and well-fed (WF; closed bars) groups. **Denotes a significant difference between the level at 1 month of age and that at 139 - to $141-\mathrm{d}$ gestation $(P<0.001)$.

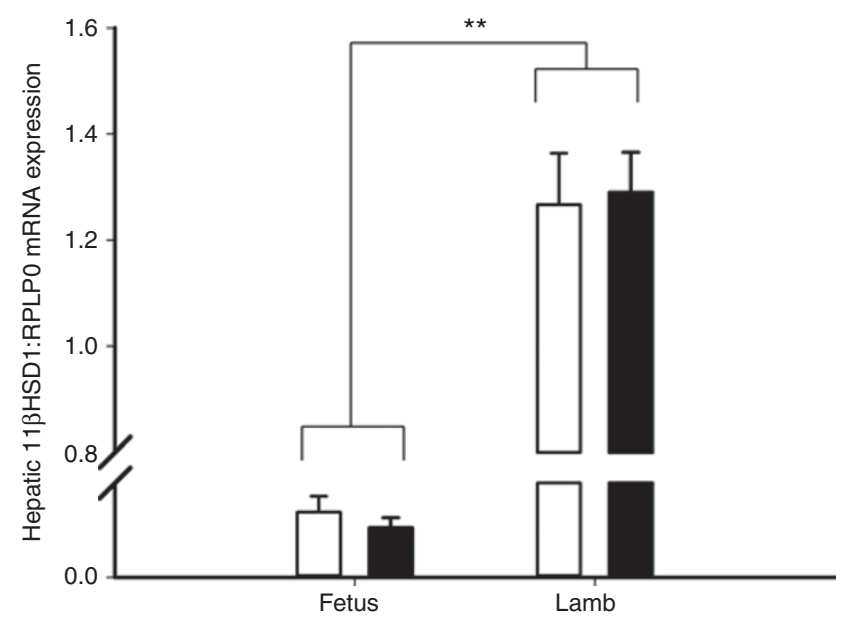

Figure 4. $11 \beta$ Hydroxysteroid dehydrogenase type 1 (11ßHSD1) mRNA expression in fetal and lamb livers in control (open bars) and well-fed (WF; closed bars) groups. ${ }^{*}$ Denotes a significant difference between the level at 1 month of age and that at 139 - to $141-d$ gestation $(P<0.01)$.

or hyperplasia of hepatocytes after the transition to the postnatal nutritional environment.

\section{Maternal Overnutrition and Hepatic Gluconeogenic Gene Expression}

An increase in maternal and fetal nutrition resulted in a significant suppression of PEPCK-M mRNA expression, and a trend toward a decrease in PEPCK-C mRNA expression in the fetal, but not postnatal liver. These data highlight that the expression of the mitochondrial and cytosolic forms of PEPCK in the fetal liver are each sensitive to an increase in the prevailing glucose and/or insulin concentrations in late gestation. Interestingly, the decrease in hepatic PEPCK-M, but not PEPCK-C, mRNA expression persisted in postnatal lambs that had been exposed to maternal overnutrition in late gestation. One possibility is that the suppression of PEPCK-M mRNA expression in

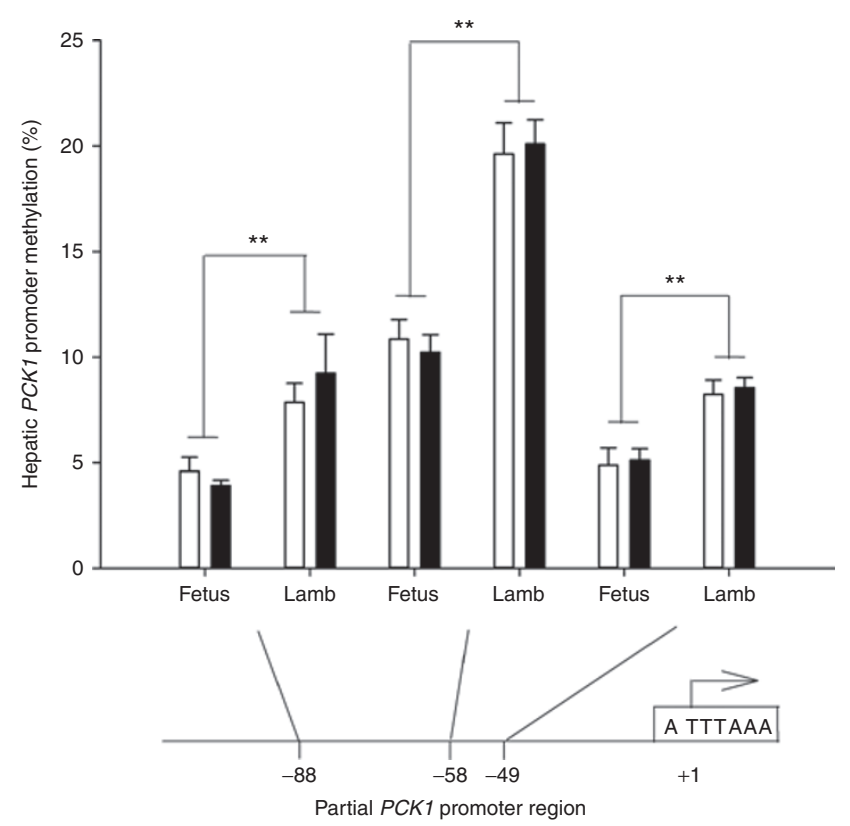

Figure 5. The level of methylation at each of the three $\mathrm{CpG}$ sites in the PCK1 promoter in the control (open bars) and well-fed (WF; closed bars) fetal sheep and lambs. ${ }^{* *}$ Denotes a significant difference between the level at 1 month of age and that at 139 - to $141-d$ gestation $(P<0.01)$.

the postnatal liver is related to the presence of higher circulating glucose concentrations in the lambs of the WF group. There was no difference, however, in the level of PEPCK-M expression between the fetal and the postnatal liver despite the markedly higher plasma glucose concentrations in postnatal, compared with that in fetal, life. Exposure to maternal overnutrition in late gestation may, therefore, program a persistent suppression of PEPCK-M expression in the offspring. PEPCK-M plays a role within the hepatic cell in balancing the cytosolic redox state during gluconeogenesis from lactate by synthesizing phosphoenolpyruvate directly in the mitochondria. This ensures that only one molecule of reduced nicotinamide adenine dinucleotide $(\mathrm{NADH})$ is produced during the production of glucose from lactate (16). Thus, a persistent suppression of PEPCK-M may have deleterious consequences for the hepatocyte in later life. Although PEPCK-C expression may be altered by a number of epigenetic modifications, including DNA and chromatin methylation (16), nothing is currently known about the factors that may result in a persistent downregulation of hepatic PEPCK-M expression.

\section{Transition to Postnatal Nutrition and Gluconeogenic Gene Expression}

Consistent with previous studies in other tissues, GLUT-1 mRNA expression was higher in the fetal than that in the postnatal liver (30). Interestingly, although it has been shown that glucose infusion into the pregnant ewe and resultant fetal hyperglycemia result in a suppression of hepatic GLUT-1 expression (30), we found no effect of the moderate increase in fetal glucose induced by increased maternal nutrition on hepatic GLUT-1 expression either before or after birth. 
Table 2. Percentage DNA methylation at the $-49,-58$, and -88 sites of the $P C K 1$ promoter region in fetuses in late gestation (139- to $141-d$ gestation) and lambs in the first month of postnatal life

\begin{tabular}{|c|c|c|c|c|}
\hline & \multicolumn{2}{|c|}{ Fetal sheep } & \multicolumn{2}{|c|}{ Postnatal lamb } \\
\hline & Control & WF & Control & WF \\
\hline PCK1 DNA methylation at -49 (\%) & $4.61 \pm 0.65$ & $3.92 \pm 0.25$ & $7.86 \pm 0.91^{* *}$ & $9.24 \pm 1.86^{* *}$ \\
\hline PCK1 DNA methylation at -58 (\%) & $4.87 \pm 0.83$ & $5.12 \pm 0.54$ & $8.24 \pm 0.67^{* *}$ & $8.56 \pm 0.47^{* *}$ \\
\hline PCK1 DNA methylation at -88 (\%) & $10.86 \pm 0.91$ & $10.22 \pm 0.84$ & $19.62 \pm 1.47^{* *}$ & $20.09 \pm 1.15^{* *}$ \\
\hline
\end{tabular}

PCK1, phosphoeno/pyruvate carboxykinase; WF, well-fed.

**Denotes a significant difference between the level at 1 month of age and that at 139- to 141-d gestation $(P<0.01)$.

There was a different impact of the transition from placental to enteral nutrition on the hepatic expression of PEPCK-M and PEPCK-C. In contrast with the expression of PEPCK-M, the level of PEPCK-C expression was significantly higher in the liver of the postnatal lamb compared with that in the liver of the fetus. Similarly, G6PHOS mRNA was expressed in the postnatal lamb liver, in contrast with the negligible level of hepatic expression of G6PHOS mRNA in fetal life. It is well established that exposure to increased glucocorticoids induces hepatic PEPCK-C and gluconeogenesis in the fetal sheep (6-9). In the present study, hepatic 11ßHSD1 mRNA expression was increased in postnatal lamb, compared with that in fetal life. Hepatic PGC-1 expression was also higher in the postnatal lamb compared with that in the fetus, and there was an emergence of a relationship between hepatic PGC-1 and PEPCK-C mRNA expression in the lamb after birth. Thus, in contrast with PEPCK-M, the transition from the fetal to the postnatal nutritional environment has a significantly greater impact on the regulation of PEPCK-C and G6PHOS than does exposure to maternal overnutrition in late gestation.

\section{Epigenetic Changes in the PCK1 Promoter After Transition to Postnatal Life}

Intriguingly, in the current study, we found that the increase in hepatic PEPCK-C expression, which occurred after birth, was associated with an increase in the level of methylation at three CpG dinucleotides $(-88,-58$, and -49$)$ upstream of the transcription start site. In contrast, it has been reported that the PCK1 gene is heavily methylated in the fetal rat liver and relatively undermethylated in the adult liver (31). Although an increase in methylation at the three sites in the $P C K 1$ promoter would be expected to result in a decrease in the binding of transcription factors, including the cyclic adenosine monophosphate (cAMP) response element-binding (CREB) protein, it is of note that the three CpG sites lie outside the "glucocorticoid regulatory unit" in PCK1. The increase in methylation at these three $\mathrm{CpG}$ dinucleotides in the PCK1 promoter region may result in a suppression of "constitutive" PCK1 expression to allow for the glucocorticoid induction of PCK1, which is important as the fetus makes the transition from continuous placental to intermittent enteral nutrition.

There was no evidence that the epigenetic state of the PCK1 promoter was altered by exposure to either maternal overnutrition or prevailing high circulating glucose concentrations in fetal or postnatal life. There is evidence from studies in the fetal baboon at 0.9 gestation that the level of methylation of a number of CpG sites $(-82,-30,-5,+31,+99$, and +105$)$ in the $P C K 1$ gene was reduced after exposure to maternal undernutrition and that this decrease was associated with an increase in hepatic PEPCK-C mRNA expression (18). It appears, therefore, that maternal undernutrition and the transition from fetal to postnatal nutrition may each play different roles in determining the epigenetic state of the PCK1 gene.

\section{Summary}

Exposure to either a restriction or an oversupply of fetal nutrients can result in long-term consequences for glucose tolerance and insulin sensitivity in later life $(32,33)$. We have investigated the impact of maternal overnutrition and separately the transition from placental to enteral nutrition on the factors that regulate hepatic gluconeogenesis, the expression of the cytosolic and mitochondrial isoforms of PEPCK, and the epigenetic status of PCK1. We have shown that there is a differential impact of exposure to prenatal overnutrition on PEPCK-M and PEPCK-C expression in the postnatal liver. Further work is required to understand the mechanism by which maternal overnutrition programs a decrease in hepatic PCK2 expression and the metabolic consequences of a decrease in PEPCK-M expression in the postnatal animal.

\section{METHODS}

\section{Animals and Feeding Regimen}

All procedures were approved by the University of Adelaide Animal Ethics Committee. Merino ewes were mated, and pregnancy was confirmed by ultrasound scanning in early gestation. From $90 \mathrm{~d}$ gestation, ewes were acclimatized to a control diet, which consisted of $1 \mathrm{~kg}$ lucerne chaff $(85 \%$ dry matter, metabolizable energy content $=8.3 \mathrm{MJ} / \mathrm{kg})$ and $300 \mathrm{~g}$ concentrated pellets containing straw, cereal, hay, clover, barley, oats, lupins, almond shells, oat husks, and limestone (89\% dry matter, metabolizable energy content $=11.6 \mathrm{MJ} / \mathrm{kg}$; Ridley Agriproducts Sheep Nutrition Ration, Murray Bridge, South Australia, Australia). The diet was calculated to provide $100 \%$ of the energy requirements for the maintenance of a pregnant ewe bearing a singleton fetus or twin fetuses as appropriate, as specified by the Ministry of Agriculture, Fisheries and Food, United Kingdom (34).

Surgery was then performed on these ewes between 103 and 113 $\mathrm{d}$ gestation (term $=147 \pm 3 \mathrm{~d}$ ) using aseptic techniques. General anesthesia was given by intravenous injection of sodium thiopentone (1.25g i.v. Pentothal; Rhone Merieux, Pinkenba, Queensland, Australia) and maintained with $2.5-4 \%$ halothane (Fluothane; ICI, Melbourne, Victoria, Australia) in oxygen. Vascular catheters were implanted in a jugular vein and carotid artery of the ewe and fetus, apart from implantation in the amniotic cavity, as previously described (35). During surgery, intramuscular injections of antibiotics $(2 \mathrm{ml}$ procaine penicillin $(250 \mathrm{mg} / \mathrm{ml})$, dihydrostreptomycin 
( $250 \mathrm{mg} / \mathrm{ml})$, procaine hydrochloride $(20 \mathrm{mg} / \mathrm{ml}$; all from Lyppards, Adelaide, South Australia, Australia), or $0.1 \mathrm{ml} / \mathrm{kg}$ terramycin 100 $(100 \mathrm{mg} / \mathrm{ml}$ oxytetracycline hydrochloride; Pfizer, New South Wales, Australia) were administered to each ewe and fetus. All catheters were filled with heparinized saline, and the fetal catheters were exteriorized through an incision in the ewe's flank. Before and after surgery, the ewes were housed in individual pens in animal holding rooms with a $12 \mathrm{~h}: 12 \mathrm{~h}$ light/dark cycle. If there was any evidence of a decline in fetal well-being after surgery, as indicated by a decline in fetal oxygenation, ampicillin $(5 \mathrm{ml})$ was administered to that fetus via the amniotic catheter for a period of $4 \mathrm{~d}$.

At $115 \mathrm{~d}$ gestation, i.e., before the commencement of the rapid fetal growth phase in late gestation (36), ewes were randomly assigned to either control $(n=14)$ or WF $(n=16)$ group. Between 115 and $124 \mathrm{~d}$ of gestation, control ewes were provided with $14.0 \pm 0.4 \mathrm{~g}$ of lucerne chaff and $6.5 \pm 0.4 \mathrm{~g}$ of pelleted concentrate per kilogram body weight, and WF ewes were provided with $22.1 \pm 0.8 \mathrm{~g}$ lucerne chaff and $10.4 \pm 0.7 \mathrm{~g}$ pelleted concentrate per kilogram body weight each day. The feed allowance of all ewes was proportionately increased by $15 \%$ every $10 \mathrm{~d}(34)$.

\section{Fetal Blood Sampling}

Between 113 and $139 \mathrm{~d}$ gestation, maternal $(5.0 \mathrm{ml})$ and fetal $(3.0 \mathrm{ml})$ arterial blood samples were collected three times per week before feeding at $0900 \mathrm{~h}$. Fetal arterial blood $(0.5 \mathrm{ml})$ was collected three times per week for determination of fetal blood gases $\left(\mathrm{PO}_{2}\right.$ and $\mathrm{PCO}_{2}$ ), oxygen saturation, $\mathrm{pH}$, hematocrit, and hemoglobin using an ABL 520 analyzer (Radiometer, Copenhagen, Denmark).

\section{Collection of Fetal Tissues}

Between 139 and $141 \mathrm{~d}$ of gestation, ewes from the control group $(n=6)$ and the WF group $(n=8)$ were killed with sodium pentobarbitone (Virbac, Peakhurst, New South Wales, Australia). Fetal sheep were delivered by hysterectomy, weighed, and killed by decapitation. Livers were weighed, and samples were collected, snap frozen in liquid $\mathrm{N}_{2}$, and stored at $-80^{\circ} \mathrm{C}$. All fetuses were singletons.

\section{Lamb Protocols and Tissue Collection}

The remaining control ( $n=8$; four carrying twins and four singletons) and WF ( $n=8$; one carrying twins and seven singletons) ewes lambed spontaneously at term. Both twins from each ewe were used in this study. After lambing, all ewes were provided with $1 \mathrm{~kg}$ lucerne chaff and $500 \mathrm{~g}$ pelleted concentrate once daily. If all feed was consumed before $1500 \mathrm{~h}$, an additional $1 \mathrm{~kg}$ of chaff was provided. After birth, each ewe and her lamb(s) were housed in an individual pen in a facility maintained at $20-22^{\circ} \mathrm{C}$ and a $12 \mathrm{~h}: 12 \mathrm{~h}$ light/dark cycle. The day of birth was designated as day 1 . Venous blood samples were collected between 0800 and $1300 \mathrm{~h}$ after 2 -h fasting on days $1-5$ and every $3 \mathrm{~d}$ thereafter until day 30. All blood samples were centrifuged at $1500 \mathrm{~g}$ for $10 \mathrm{~min}$, and the plasma was stored at $-20^{\circ} \mathrm{C}$.
At $30 \mathrm{~d}$ of age, the lambs were killed with an overdose of sodium pentobarbitone (Virbac). Livers were dissected out and weighed, and samples were snap frozen in liquid $\mathrm{N}_{2}$ and stored at $-80^{\circ} \mathrm{C}$.

\section{Plasma Glucose}

Plasma glucose concentrations were measured by enzymatic analysis using hexokinase and glucose-6-phosphate dehydrogenase to measure the formation of NADH photometrically at $340 \mathrm{~nm}$ (COBAS MIRA automated analysis system; Roche Diagnostica, Basel, Switzerland) (35). The sensitivity of the assay was $0.5 \mathrm{mmol} / \mathrm{l}$, and the intra- and interassay coefficients of variation were both $<5 \%$.

\section{Plasma Insulin}

Plasma insulin concentrations were measured using a radioimmunoassay (Rat Insulin kit; Linco Research, St Louis, MO), which was validated for use with sheep plasma (37). The sensitivity of the assay was $0.01 \mathrm{ng} / \mathrm{ml}$, and the intra- and interassay coefficients of variation were both $<10 \%$.

\section{Plasma Cortisol}

Cortisol was extracted from fetal plasma using dichloromethane as previously described (38). Fetal cortisol concentrations were then measured using an Orion Diagnostica Radioimmunoassay kit (Orion Diagnostica, Turku, Finland) previously validated for fetal sheep plasma (39). The interassay coefficient of variation was $20 \%$, and the intraassay coefficient of variation was $<10 \%$.

\section{RNA Extraction}

RNA from the dorsal lobe of the liver $(\sim 30 \mathrm{mg})$ was extracted using Trizol reagent (Invitrogen Australia, Mount Waverley, Victoria, Australia) and chloroform. RNA was treated with 50\% ethanol and run through a purification process using the RNeasy Mini Kit (QIAGEN Australia, Doncaster, Victoria, Australia). The quality and concentration of the RNA were determined by measuring absorbance at 260 and $280 \mathrm{~nm}$, and RNA integrity was confirmed by agarose gel electrophoresis. cDNA was then synthesized using the purified RNA $(\sim 5 \mu \mathrm{g})$, Superscript III Reverse Transcriptase (Invitrogen Australia) and random hexamers.

\section{Quantitative Real-Time Reverse Transcription-PCR}

The relative expression levels of PGC-1, PPAR $\alpha$, PEPCK-M, PEPCK-C, G6PHOS, GLUT-1, GR, and 11ßHSD1 mRNA transcripts were measured by quantitative real-time reverse transcription-PCR (qRT-PCR) using the SYBR Green system in an ABI prism 7900 Sequence Detection System (PE Applied Biosystems, Foster City, CA) (40). For each transcript, qRT-PCR was performed using specific primers (Table 3 ). Each amplicon was designed to be $\sim 200 \mathrm{bp}$ in length, sequenced to ensure the authenticity of the DNA product, and $\mathrm{qRT}-\mathrm{PCR}$ melting curve analysis was performed to demonstrate amplicon homogeneity. Controls containing no reverse transcriptase were also used. For the qRT-PCR measurements, the primer

Table 3. Sequences of real-time PCR primers for hepatic and reference genes

\begin{tabular}{|c|c|c|c|}
\hline Gene name (GenBank accession no.) & Forward $\left(5^{\prime}-3^{\prime}\right)$ & Reverse $\left(5^{\prime}-3^{\prime}\right)$ & Amplicon size (bp) \\
\hline PGC-1 (AY237127) & $5^{\prime}$-tctggaactgcaggcctaactc- $3^{\prime}$ & $5^{\prime}$-gcaagagggcttcagctttg-3' & 96 \\
\hline PPAR $\alpha$ A (Y369138) & $5^{\prime}$-cgtgtgaacatgacctagaag- $3^{\prime}$ & $5^{\prime}$-acgaagggcggattgttg-3' & 151 \\
\hline PEPCK-C (NM174737) & $5^{\prime}$-aactcacggttctgcactcca-3' & $5^{\prime}$-ggtcgtgcatgatgactttgc $-3^{\prime}$ & 115 \\
\hline G6PHOS (NM013098) & $5^{\prime}$-gaaggccaagagatggtgtga $-3^{\prime}$ & $5^{\prime}$-tgcagctcttgcggtacatg-3' & 137 \\
\hline GR (NM001114186) & $5^{\prime}$-actgccccaagtgaaaacaga- $3^{\prime}$ & $5^{\prime}$-atgaacagaaatggcagacattttatt-3' & 230 \\
\hline 11ßHSD1 (X69561) & $5^{\prime}$-gcgccagatccctgtctgat-3' & $5^{\prime}$-agccccataccaccttcttt-3' & 250 \\
\hline RPLP0 (BT021080) & $5^{\prime}$-caaccctgaagtgcttgacat-3' & $5^{\prime}$-aggcagatgcatcagcca-3' & 227 \\
\hline
\end{tabular}

11ßHSD1, $11 \beta$ hydroxysteroid dehydrogenase type 1; G6PHOS, glucose-6-phosphatase; GLUT1, glucose transporter-1; GR, glucocorticoid receptor; PEPCK, phosphoeno/pyruvate carboxy kinase; PGC-1, peroxisome proliferator-activated receptor $\gamma$ coactivator 1; PPAR, peroxisome proliferator-activated receptor. 
concentrations were equivalent for all genes, and the amplification efficiencies were $0.981-0.999$. A constant amount of cDNA equating to $10 \mathrm{ng}$ of total RNA was used for each qRT-PCR measurement, and three technical replicates were performed in duplicate for each gene.

Each qRT-PCR reaction ( $5 \mu$ total volume) contained the following: $2.5 \mu \mathrm{l}$ of $2 \times$ SYBR Green master mix (Applied Biosystems), $0.25 \mu \mathrm{l}$ of each primer giving a final concentration of $450 \mu \mathrm{l}, 1.0 \mu \mathrm{l}$ of molecular grade $\mathrm{H}_{2} \mathrm{O}$, and $1.0 \mu \mathrm{l}$ of a 1:10 dilution of the stock template. The cycling conditions consisted of 40 cycles of $95^{\circ} \mathrm{C}$ for $15 \mathrm{~s}$ and $60^{\circ} \mathrm{C}$ for $1 \mathrm{~min}$. At the end of each run, a dissociation curve was obtained.

The abundance of each mRNA transcript was measured, and its expression relative to that of ribosomal protein large subunit P0 (RPLP0) was calculated using Q-gene qRT-PCR analysis software. There were no differences in the expression of the housekeeper gene between the control and the WF groups in either the fetal or the postnatal cohort.

\section{Combined Bisulfite Restriction Analysis}

DNA methylation within the PCK1 promoter region was analyzed using the combined bisulfite restriction assay (COBRA) (41). Briefly, $\sim 2 \mu \mathrm{g}$ of DNA from the ventral lobe of fetal and lamb liver was subjected to bisulfite conversion (EpiTect; QIAGEN Australia). PCR was then performed on $100 \mathrm{ng}$ of bisulfite-converted DNA using primers (forward: 5' TAAAGGTTTGTTATGGTTGGTTTAG 3'; reverse: 3' CTAACCTTTAAATTCCAAAAAAA $5^{\prime}$ ) and conditions that amplified methylated and unmethylated templates with no bias. The amplicon contained three CpG sites at $-49,-58$, and -88 , where +1 denotes the transcription start site. COBRA was performed using restriction endonucleases that cleave only those amplicons derived from methylated templates. The PCK1 amplicon was digested with $20 \mathrm{U}$ of TaqI (Thermo Fisher Scientific, Scoresby, Victoria, Australia), MaeII, and DpnII (New England Biolabs, Ipswich, MA), which digest methylated templates at $-49,-58$, and -88 , respectively. The intensity of uncut and cut fragments was quantified using the ExperionTM Automated Electrophoresis System (Bio-Rad, Hercules, CA). The percentage of methylation was estimated by measuring the ratio of cut to total PCR product.

\section{Statistical Analyses}

Data are presented as the mean \pm SEM. The fetal cohort comprised six control fetuses (four males and two females) and eight fetuses from WF ewes (three males and five females). The postnatal lamb cohort comprised 12 control lambs ( 6 males and 6 females) and 9 lambs in the WF group ( 3 males and 6 females). There were 14 singleton and no twins in the fetal group; and 11 singletons and 10 twins in the postnatal lamb group. Using multifactorial ANOVA, we found no significant effect (main effect or interaction with treatment group) of being a twin or of the sex of the lamb on the expression of any hepatic mRNA level and, therefore, data were combined for subsequent analyses. Two-way ANOVA was then used to determine the main effects of maternal nutritional treatment (control vs. WF), developmental age (fetal vs. postnatal), and their interaction on birth weight, liver mass, hepatic gene expression, and the level of PCK1 methylation. Simple linear regression analyses were used to determine the relationships between postnatal measures of fat mass, plasma nutrient, and hormone concentrations and the gluconeogenic gene expression. Plasma glucose, insulin, and cortisol concentrations across the postnatal weeks 1-4 were averaged for correlation analyses, unless stated otherwise. Partial correlation analysis was used to control the effects of maternal intake or mean plasma glucose levels where appropriate. A probability of $5 \%(P<0.05)$ was considered the level of significance in all analyses.

\section{ACKNOWLEDGMENTS}

The authors thank Anne Jurisevic and Laura O'Carroll for expert assistance with animal surgery and maintenance.

\section{STATEMENT OF FINANCIAL SUPPORT}

This work was supported by the National Health and Medical Research Council of Australia (NHMRC) (to I.C.Mc.M.). B.S.M. was supported by a Peter
Doherty Fellowship from NHMRC, and J.L.M. was supported by a Fellowship from the South Australian Cardiovascular Research Network.

\section{REFERENCES}

1. Buchanan TA, Kjos SL. Gestational diabetes: risk or myth? J Clin Endocrinol Metab 1999;84:1854-7.

2. Catalano PM, Thomas A, Huston-Presley L, Amini SB. Phenotype of infants of mothers with gestational diabetes. Diabetes Care 2007;30 Suppl 2:S156-60.

3. Dörner G, Plagemann A. Perinatal hyperinsulinism as possible predisposing factor for diabetes mellitus, obesity and enhanced cardiovascular risk in later life. Horm Metab Res 1994;26:213-21.

4. Martin RJ, Hausman GJ, Hausman DB. Regulation of adipose cell development in utero. Proc Soc Exp Biol Med 1998;219:200-10.

5. Plagemann A, Harder T, Kohlhoff R, Rohde W, Dörner G. Glucose tolerance and insulin secretion in children of mothers with pregestational IDDM or gestational diabetes. Diabetologia 1997;40:1094-100.

6. Fowden AL, Mijovic J, Silver M. The effects of cortisol on hepatic and renal gluconeogenic enzyme activities in the sheep fetus during late gestation. J Endocrinol 1993;137:213-22.

7. Gentili S, Morrison JL, McMillen IC. Intrauterine growth restriction and differential patterns of hepatic growth and expression of IGF1, PCK2, and HSDL1 mRNA in the sheep fetus in late gestation. Biol Reprod 2009;80:1121-7.

8. Rozance PJ, Limesand SW, Barry JS, et al. Chronic late-gestation hypoglycemia upregulates hepatic PEPCK associated with increased PGClalpha mRNA and phosphorylated CREB in fetal sheep. Am J Physiol Endocrinol Metab 2008;294:E365-70.

9. Warnes DM, Seamark RF, Ballard FJ. The appearance of gluconeogenesis at birth in sheep. Activation of the pathway associated with blood oxygenation. Biochem J 1977;162:627-34.

10. Cooper MS, Stewart PM. 11Beta-hydroxysteroid dehydrogenase type 1 and its role in the hypothalamus-pituitary-adrenal axis, metabolic syndrome, and inflammation. J Clin Endocrinol Metab 2009;94:4645-54.

11. Jamieson PM, Nyirenda MJ, Walker BR, Chapman KE, Seckl JR. Interactions between oestradiol and glucocorticoid regulatory effects on liver-specific glucocorticoid-inducible genes: possible evidence for a role of hepatic 11beta-hydroxysteroid dehydrogenase type 1. J Endocrinol 1999;160: 103-9.

12. Nyirenda MJ, Lindsay RS, Kenyon CJ, Burchell A, Seckl JR. Glucocorticoid exposure in late gestation permanently programs rat hepatic phosphoenolpyruvate carboxykinase and glucocorticoid receptor expression and causes glucose intolerance in adult offspring. J Clin Invest 1998;101: 2174-81.

13. Hanson RW. Thematic minireview series: a perspective on the biology of phosphoenolpyruvate carboxykinase 55 years after its discovery. J Biol Chem 2009;284:27021-3.

14. Hanson RW, Patel YM. Phosphoenolpyruvate carboxykinase (GTP): the gene and the enzyme. Adv Enzymol Relat Areas Mol Biol 1994;69:203-81.

15. Hanson RW, Reshef L. Regulation of phosphoenolpyruvate carboxykinase (GTP) gene expression. Annu Rev Biochem 1997;66:581-611.

16. Yang J, Kalhan SC, Hanson RW. What is the metabolic role of phosphoenolpyruvate carboxykinase? J Biol Chem 2009;284:27025-9.

17. Yang J, Reshef L, Cassuto H, Aleman G, Hanson RW. Aspects of the control of phosphoenolpyruvate carboxykinase gene transcription. J Biol Chem 2009;284:27031-5.

18. Nijland MJ, Mitsuya K, Li C, et al. Epigenetic modification of fetal baboon hepatic phosphoenolpyruvate carboxykinase following exposure to moderately reduced nutrient availability. J Physiol (Lond) 2010;588(Pt 8): 1349-59.

19. Bollo E, Bassano B, Peracino V, Biolatti B. Effect of emanciation on liver histology of alpine chamois during winter. J Wildl Dis 1999;35:770-3.

20. Burns SP, Desai M, Cohen RD, et al. Gluconeogenesis, glucose handling, and structural changes in livers of the adult offspring of rats partially deprived of protein during pregnancy and lactation. J Clin Invest 1997;100:1768-74. 
21. El-Khattabi I, Grégoire F, Remacle C, Reusens B. Isocaloric maternal lowprotein diet alters IGF-I, IGFBPs, and hepatocyte proliferation in the fetal rat. Am J Physiol Endocrinol Metab 2003;285:E991-E1000.

22. Hyatt MA, Gopalakrishnan GS, Bispham J, et al. Maternal nutrient restriction in early pregnancy programs hepatic mRNA expression of growthrelated genes and liver size in adult male sheep. J Endocrinol 2007;192: $87-97$.

23. McMillen IC, Adams MB, Ross JT, et al. Fetal growth restriction: adaptations and consequences. Reproduction 2001;122:195-204.

24. Ozanne SE, Smith GD, Tikerpae J, Hales CN. Altered regulation of hepatic glucose output in the male offspring of protein-malnourished rat dams. Am J Physiol 1996;270(4 Pt 1):E559-64.

25. Mirghani H, Zayed R, Thomas L, Agarwal M. Gestational diabetes mellitus: fetal liver length measurements between 21 and 24 weeks' gestation. J Clin Ultrasound 2007;35:34-7.

26. Guo F, Jen KL. High-fat feeding during pregnancy and lactation affects offspring metabolism in rats. Physiol Behav 1995;57:681-6.

27. Buckley AJ, Keserü B, Briody J, Thompson M, Ozanne SE, Thompson CH. Altered body composition and metabolism in the male offspring of high fat-fed rats. Metab Clin Exp 2005;54:500-7.

28. Merzouk H, Madani S, Hichami A, Prost J, Belleville J, Khan NA. Agerelated changes in fatty acids in obese offspring of streptozotocin-induced diabetic rats. Obes Res 2002;10:703-14.

29. Muhlhausler BS, Duffield JA, McMillen IC. Increased maternal nutrition increases leptin expression in perirenal and subcutaneous adipose tissue in the postnatal lamb. Endocrinology 2007;148:6157-63.

30. Das UG, Schroeder RE, Hay WW Jr, Devaskar SU. Time-dependent and tissue-specific effects of circulating glucose on fetal ovine glucose transporters. Am J Physiol 1999;276(3 Pt 2):R809-17.

31. Benvenisty N, Mencher D, Meyuhas O, Razin A, Reshef L. Sequential changes in DNA methylation patterns of the rat phosphoenolpyru- vate carboxykinase gene during development. Proc Natl Acad Sci USA 1985;82:267-71.

32. Girard J. Gluconeogenesis in late fetal and early neonatal life. Biol Neonate 1986;50:237-58.

33. Hay WW Jr. Fetal and neonatal glucose homeostasis and their relation to the small for gestational age infant. Semin Perinatol 1984;8: 101-16.

34. Alderman GA, Morgan DE, Harvard A, Edwards RE, Todd JR. Energy allowances and feeding systems for ruminants. Ministry of Agriculture, Fisheries and Food: Technical Bulletin 33. London: Her Majesty's Stationery Office; 1975.

35. Edwards LJ, Symonds ME, Warnes KE, et al. Responses of the fetal pituitary-adrenal axis to acute and chronic hypoglycemia during late gestation in the sheep. Endocrinology 2001;142:1778-85.

36. Fowden A. Nutrient requirements for normal fetal growth and metabolism. In: Hanson M, Spencer J, Rodeck C, eds. Fetus and Neonate: Physiology and Clinical Applications, 1 st edn. Cambridge: Cambridge University Press; 1995:31-56.

37. Muhlhausler BS, Adam CL, Findlay PA, Duffield JA, McMillen IC. Increased maternal nutrition alters development of the appetite-regulating network in the brain. FASEB J 2006;20:1257-9.

38. Bocking AD, McMillen IC, Harding R, Thorburn GD. Effect of reduced uterine blood flow on fetal and maternal cortisol. J Dev Physiol 1986;8: 237-45.

39. Edwards LJ, Coulter CL, Symonds ME, McMillen IC. Prenatal undernutrition, glucocorticoids and the programming of adult hypertension. Clin Exp Pharmacol Physiol 2001;28:938-41.

40. Heid CA, Stevens J, Livak KJ, Williams PM. Real time quantitative PCR. Genome Res 1996;6:986-94.

41. Xiong Z, Laird PW. COBRA: a sensitive and quantitative DNA methylation assay. Nucleic Acids Res 1997;25:2532-4. 